\title{
Protective effects of tumor necrosis factor alpha inhibitors on methotrexate-induced pancreatic toxicity
}

\author{
Tolga Mercantepe ${ }^{1, A-E}$, Yildıray Kalkan ${ }^{1, A-E}$, Levent Tumkaya ${ }^{1, A-E}$, Ibrahim Sehitoglu ${ }^{2, A-C}$, Filiz Mercantepe ${ }^{3, D, E}$, Sermet Ylldırmı $5^{4, C}$ \\ 1 Departments of Histology and Embryology, Faculty of Medicine, Recep Tayyip Erdogan University, Rize, Turkey \\ ${ }^{2}$ Department of Pathology, Faculty of Medicine, Recep Tayyip Erdogan University, Rize, Turkey \\ ${ }^{3}$ Department of Internal Medicine, Faculty of Medicine, Recep Tayyip Erdogan University, Rize, Turkey \\ ${ }^{4}$ Department of Pathology, Faculty of Medicine, Karadeniz Technical University, Trabzon, Turkey \\ A - research concept and design; $\mathrm{B}$ - collection and/or assembly of data; $\mathrm{C}$ - data analysis and interpretation; \\ $D$ - writing the article; $E$ - critical revision of the article; $F$ - final approval of the article
}

Address for correspondence

Tolga Mercantepe

E-mail: tolgamercantepe@yahoo.com

\section{Funding sources}

This study was supported by the Scientific Research Department of Recep Tayyip Erdogan University, Turkey (Project No BAP: 2015.53001.106.01.03).

\section{Conflict of interest}

None declared

Received on January 12, 2016

Reviewed on January 27, 2017

Accepted on February 14, 2017
DOI

10.17219/acem/68967

\section{Copyright}

Copyright by Author(s)

This is an article distributed under the terms of the

Creative Commons Attribution Non-Commercial License

(http://creativecommons.org/licenses/by-nc-nd/4.0/)

\section{Abstract}

Background. Methotrexate (MTX), a folate antagonist, is commonly used in the treatment of many different types of cancer and inflammatory diseases, including pancreatic cancer, although its side effects on the pancreas have not yet been researched. The mechanism of MTX-induced toxicity is not well known, and it has been reported in high-dose toxicity studies that the pancreas is sensitive to toxic effects.

Objectives. The aim of our study was to determine whether adalimumab (ADA) has a preventive effect on MTX-induced pancreas toxicity in rats.

Material and methods. The rats were equally and randomly divided into 3 groups (Group 1 comprised the healthy controls, Group 2 was the MTX group, and Group 3 was the MTX + ADA group). The rats in Groups 2 and 3 received an intraperitoneal (ip.) single-dose injection of MTX (20 mg/kg). A single dose of $5 \mathrm{mg} / \mathrm{kg}$ ADA (REMICADE ${ }^{\circledR}$ ) was administered ip. to Group 3. All the rats were sacrificed under anesthesia 5 days after receiving the MTX injection.

Results. Significantly higher mean edema, necrotic cell, and inflammatory scores were recorded in Groups 2 and 3 compared to those recorded in Group 1. Significantly decreased edema, number of necrotic cells, and inflammatory scores were noted in Group 3 than in Group 2. A decrease in islets of Langerhans cell insulin and somatostatin-positive interneurons was demonstrated after the administration of MTX. An increase in insulin and somatostatin-positive cells in islets of Langerhans, as well as a remodeling of the structure of the pancreas, was shown following treatment with ADA.

Conclusions. Adalimumab was demonstrated to have a protective effect against MTX-induced pancreatic injury in this study.

Key words: adalimumab, methotrexate, pancreas, rat, toxicity 


\section{Introduction}

Methotrexate (MTX) was discovered in 1948 by Farber as an effective treatment for acute leukemia and is an antimetabolite, antifolate, and chemotherapeutic drug. ${ }^{1,2}$ The effect of DNA synthesis in the " $\mathrm{S}$ " phase by inhibition and the affinity of dihydrofolic acid to inhibit the dihydrofolate reductase enzyme appear with the use of MTX. Thus, there is a drop in tetrahydrofolic acid levels and purine synthesis is inhibited., ${ }^{3,4}$ Methotrexate is used to treat many different types of cancer (colorectal, breast, and pancreatic cancers) and inflammatory diseases (rheumatoid arthritis - RA, psoriatic arthritis, systemic lupus erythematosus, and dermatomyositis) ${ }^{1-5}$ Nevertheless, its use is associated with side effects such as fibrosis affecting the liver, lung, and other organs. ${ }^{1,2,5}$ Acute intense MTX side effects are dose-dependent. Bone marrow suppression, gastrointestinal upsets or ulcers, and liver fibrosis are well-known acute or common side effects of MTX therapy. It has been proposed in recent studies that MTX has a cytotoxic effect in reducing intracellular tetrahydrofolate, but the mechanism of MTX-induced toxicity is not well known., ${ }^{1,2,-11}$

Methotrexate has been used in the treatment of pancreatic cancer, but there has been no research into its side effects on the pancreas, an organ which is relatively sensitive to various toxic substances and drugs. High-dose substances, causing oxidative stress, have been reported to have a toxic effect on the pancreas. ${ }^{1,5-11}$ However, the development of tolerance to MTX has been reported in patients over time. The tolerance mechanism of the metabolites in MTX is not known. ${ }^{1,2,4,5,11}$ Physicians increase the dosage of MTX to counter the development of tolerance. Accordingly, the risk of MTX toxicity increases. It was found in recent studies that an MTX overdose caused oxidative stress, leading to the release of proinflammatory cytokines and further tissue damage. ${ }^{5,6,11}$

Tumor necrosis factor alpha (TNF- $\alpha$ ) plays a key role in the mechanism of immune-mediated inflammatory diseases, such as RA, ankylosing spondylitis, Crohn's disease, ulcerative colitis, psoriasis, and psoriatic arthritis. Inflammation induces the overproduction of inflammatory cytokines, such as TNF- $\alpha$, interleukin: IL-1 $\beta$, IL-6, IL-15, and IL-18, while TNF- $\alpha$ has been shown to increase the number of pancreatic cancer cells. ${ }^{12}$ It has been reported in the literature that TNF- $\alpha$ cytokines modulate the autocrine growth regulatory pathways in pancreatic cancer cells. ${ }^{13}$ Antagonists of TNF- $\alpha$, such as adalimumab (ADA), infliximab, etanercept (ETN), golimumab, and certolizumab pegol, have been widely used in the treatment of RA. Inhibition of TNF results in the down-regulation of abnormal and progressive inflammatory processes, resulting in the prevention of target organ damage. ${ }^{12,13}$

It has been found that a combination of TNF- $\alpha$ antagonists and MTX improves the symptoms and signs of inflammation and physical function in RA patients who do not respond to MTX alone. ${ }^{10-13}$ The combination of MTX and ADA has not been studied for its ability to counter toxicity in the pancreas. Irreversible tissue injury from edema and inflammatory and acinar necrosis has been reported in histopathological studies on pancreatic toxicity. ${ }^{14-16}$

The aim of this study was to determine whether TNF- $\alpha$ inhibitors have a preventive or toxicity-enhancing effect on MTX-induced pancreatic toxicity.

\section{Material and methods}

\section{Animal testing}

Thirty male albino Sprague Dawley ${ }^{\circledR}$ rats, aged 3 months and weighing 250-300 g, were procured from the Animal Care and Research Unit for this study (Recep Tayyip Erdogan University, Rize, Turkey). The animals were kept at a constant temperature $\left(21 \pm 3^{\circ} \mathrm{C}\right)$ and according to a constant photoperiod and temperature regime (12-h light/dark cycle).

During the experimental period, all of the subjects were given fed ad libitum pellets containing $21 \%$ crude protein (purina) and given drinking water daily. The animals were selected according to the criteria outlined in the Guide for the Care and Use of Laboratory Animals, prepared by the National Academy of Sciences and published by the National Institutes of Health. Recep Tayyip Erdogan University Animal Care and Research Unit (Rize, Turkey).

This study was approved by the Institutional Animal Ethical Committee Recep Tayyip Erdogan University Animal Care and Research Unit (Rize, Turkey).

The subjects were randomly allocated to 3 groups of 8 rats each $(\mathrm{n}=8)$, with similar biological and physiological characteristics: Group 1: control group (healthy), Group 2: MTX group and Group 3: MTX + ADA group.

Isotonic saline solution, mixed with an equal volume of MTX, was administered by ip. injection to Group 1.

A single-dose injection of MTX (Emthexate-s ${ }^{\circledR}, 50-\mathrm{mg}$ ampule), at a dose of $20 \mathrm{mg} / \mathrm{kg}$, was given by ip. injection to Groups 2 and 3, and a single dose of $5 \mathrm{mg} / \mathrm{kg}$ ADA $\left(\right.$ REMICADE $^{\circledR}$ ) was administered ip. to Group 3.

All the rats were sacrificed under anesthesia with ketamine hydrochloride $50 \mathrm{mg} / \mathrm{kg}$, intramuscularly (Ketalar, Parke-Davis, Istanbul, Turkey) 5 days after receiving the MTX injection.

\section{Histological preparation}

Pancreatic tissue samples were fixed in 10\% formalin. After fixation, the specimens were dehydrated in an ascending series of alcohol, cleared in xylene, and embedded in paraffin. The paraffin blocks were cut 4-5 $\mu \mathrm{m}$ thick, using a microtome (Leica ${ }^{\circledR}$ RM2125 RTS), and the sections were stained with hematoxylin and eosin (Applichem GmbH, Darmstadt, Germany), according to the guidelines that govern conventional light microscopes. 


\section{Immunohistochemical preparation}

Paraffin blocks of the pancreatic samples were cut into 1-2 $\mu \mathrm{m}$ semi-thin sections. The sections obtained for immunohistochemical staining were left in xylene for $10 \mathrm{~min}$, twice, and after being passed through an alcohol series (70-99\%) for $5 \mathrm{~min}$, were kept in a $3 \% \mathrm{H}_{2} \mathrm{O}_{2}$ solution for $10 \mathrm{~min}$. After washing with phosphate buffered saline solution (PBS), they were heated 4 times in a citrate buffer for 5-10 min at $800 \mathrm{~W}$ of power, and allowed to stand for $20 \mathrm{~min}$ in a secondary blocking agent. Each preparation was allowed to stand for 60-75 min in various dilutions (1/50-1/200) of anti-laminin antibody staining (Polyclonal Guinea Pig Anti-Insulin ${ }^{\circledR}$ [clinical application for IS002], and Polyclonal Rabbit Anti-Human Somtastatin ${ }^{\circledR}$ [clinical application for A0566], both Dako Denmark A/S, Denmark). The 3,3'-diaminobenzidine (DAB) solution was used as a chromogenic dye, and stained with Mayer's hematoxylin for contrast dye. Phosphate buffered saline solution was used for the negative controls instead of primary antibodies. The preparation was closed off with a suitable agent and photographed. According to the blind scoring evaluation performed by 2 histologists, the positivity was divided into the following 4 categories according to the percentage value: mild $(+)$, moderate $(++)$, severe $(+++)$, and very severe $(++++)$.

\section{Pathological assessment of tissue}

Parts of the tissue were fixed and embedded in paraffin for histological analysis. Blinded pathological scoring of the pancreas, by an experienced pathologist from Recep Tayyip Erdoğan University, Rize, Turkey, was performed with respect to edema, bleeding, inflammatory cell infiltration, and necrosis, according to Schmidt's report (Table 1). ${ }^{14}$

\section{Statistical analysis}

Statistical analysis was performed using $\operatorname{SPSS}^{\circledR}$ v. 18 (IBM; Chicago, USA). Schmidt's score was calculated. ${ }^{14}$ The data was expressed as mean \pm standard error of the mean (SEM). Statistical analysis was performed using one-way analysis of variance, followed by Tukey's test for each paired experiment value. A p-value of $\mathrm{p}<0.05$ was considered to be significant. The sections obtained by immunohistochemical staining were evaluated and graded by 2 blinded histologists and the positivity was expressed in terms of percentage and divided into 4 grade categories. Data was expressed as median \pm standard deviation (SD). The obtained values were statistically compared with the Kruskal-Wallis test $(\mathrm{p}<0.05)$ to each other.

\section{Results}

\section{Histological results}

The morphologic structure of the tissues in the control group was observed to have a normal histology (Fig. 1A, 1B).

The histopathologic features of the Group 2 samples were atypical islets of Langerhans, mild edema, necrosis, and inflammatory infiltration. Necrotic cells were observed in the islets of Langerhans and acinar cells. Necrotic acinar cells, with a pyknotic nucleus in the center, partial karyorrhexis, and a bright border due to cytoplasmatic shrinkage and cell degeneration, were observed. Connective tissue trabeculae were noted to increase considerably in volume with leukocytic infiltration (Fig. 1C-1E).

Complete destruction of islet of Langerhans cells, due to the toxicity of MTX, appeared in the Group II rats compared to Group 1 (Fig. 1A-1D).

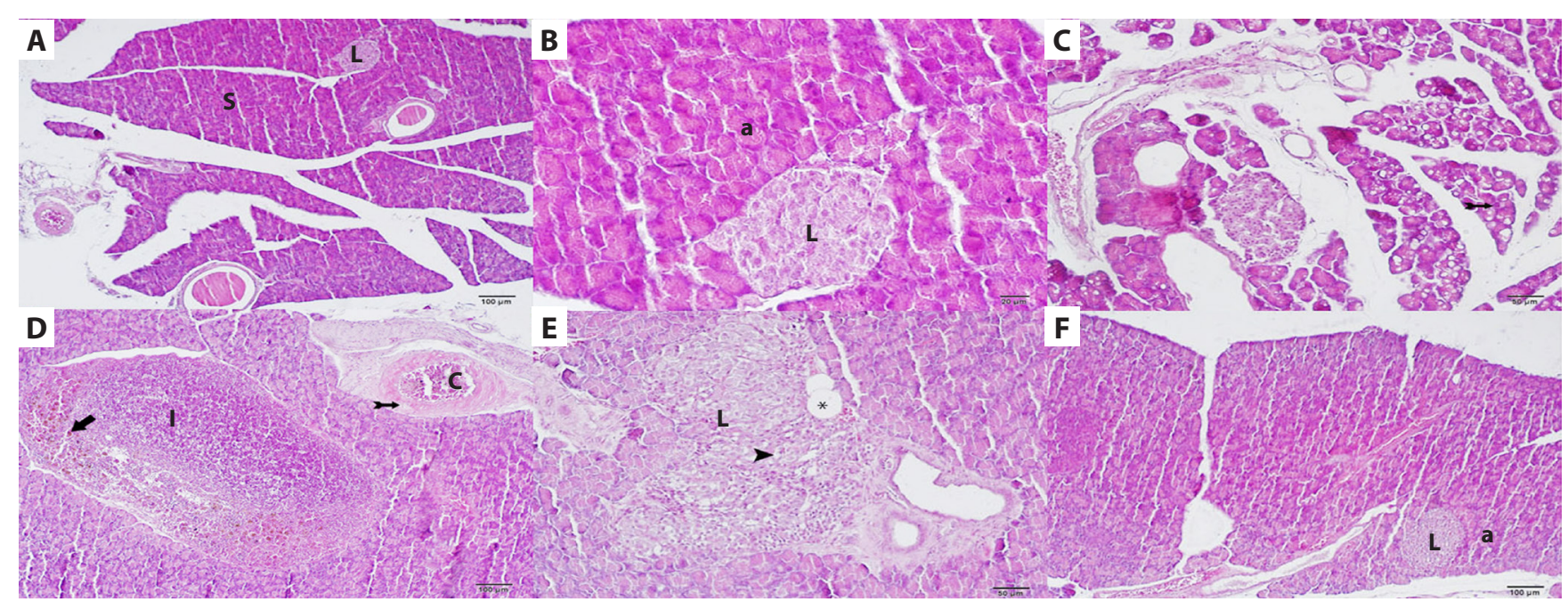

Fig. 1. A, B - histology of a normal pancreas ( $L$ - islets of Langerhans, a - acinar); $C, D, E-M T X$ group $C$ - MTX group demonstrating necrotic acinar cells with a pyknotic nucleus (tailed arrow), and edema (E); D - there are numerous entirely destroyed lobules with extreme leukocytic infiltration (I) and frequently widespread hemorrhage (thick arrow), capillary congestion (c), atypical blood vessel (thin arrow); E - edema (asterisk) and mononuclear leukocyte infiltration were observed in islets of Langerhans (spiral arrow); F - MTX + ADA group ( $L$ - islet of Langerhans, a - acinar); H\&E stains. 
Decreased edema, necrosis, and inflammatory infiltration was demonstrated in the Group 3 samples.

A decrease in necrotic cells was also observed in islets of Langerhans and acinar cells (Fig. 1F) after the administration of the ADA/MTX combination therapy.

\section{Immunohistochemical results}

The immunoreactivity rate for anti-insulin, together with islets of Langerhans, was found to be moderate (17\%), severe (33\%), and very severe $(50 \%)$ in Group 1; mild (67\%) and moderate (33\%) in Group 2; and mild (17\%), moderate (33\%), severe (33\%), and very severe $(17 \%)$ in Group 3 (Fig. 2, 3).

Anti-somatostatin immunopositivity in islets of Langerhans was shown on immunohistochemical staining using the immunoperoxidase method, and was found to be mild (17\%), moderate (17\%), severe (33\%), and very severe $(33 \%)$ in Group 1; mild (83\%) and moderate (17\%) in Group 2; and mild (17\%), moderate (33\%), and very severe $(50 \%)$ in Group 3 (Table 3).

\section{Stereological results}

All the study rats were scored by both investigators using Schmidt's histopathological scoring method. There was no more than a 0.5 -point deviation in their discernment. Schmidt's histopathological scoring steps, shown in Table 2, were applied.

\section{Statistical results}

Significantly higher mean edema, necrotic cell, and inflammatory scores, compared to those obtained for Group 1 , were recorded for Group $2(\mathrm{p}<0.05)$. Significantly decreased edema, necrotic cell, and inflammatory scores were recorded for Group 3, when compared to Group 2 ( $<$ < 0.05) (Table 2).
Table 1. Schmidt's histopathologic scoring criteria

\begin{tabular}{|c|c|}
\hline & Edema \\
\hline $\begin{array}{l}0 \\
0.5 \\
1 \\
1.5 \\
2 \\
2.5 \\
3 \\
3.5 \\
4\end{array}$ & $\begin{array}{l}\text { Absent } \\
\text { Focal expansion of interlobular septae } \\
\text { Diffuse expansion of interlobular septae } \\
\text { Same as } 1+\text { focal expansion of interlobular septae } \\
\text { Same as } 1+\text { diffuse expansion of interlobular septae } \\
\text { Same as } 2+\text { focal expansion of interacinar septae } \\
\text { Same as } 2+\text { diffuse expansion of interacinar septae } \\
\text { Same as } 3 \text { + focal expansion of intercellular spaces } \\
\text { Same as } 3 \text { + diffuse expansion of intercellular spaces }\end{array}$ \\
\hline & Acinar necrosis \\
\hline $\begin{array}{l}0 \\
0.5 \\
1 \\
1.5 \\
2 \\
2.5 \\
3 \\
3.5 \\
4\end{array}$ & $\begin{array}{l}\text { Absent } \\
\text { Focal occurrence of 1-4 necrotic cells/HPF } \\
\text { Diffuse occurrence of 1-4 necrotic cells/HPF } \\
\text { Same as } 1+\text { focal occurrence of } 5-10 \text { necrotic cells/HPF } \\
\text { Diffuse occurrence of 5-10 necrotic cells/HPF } \\
\text { Same as } 2+\text { focal occurrence of } 11-16 \text { necrotic cells/HPF } \\
\text { Diffuse occurrence of } 11-16 \text { necrotic cells/HPF } \\
\text { (foci of confluent necrosis) } \\
\text { Same as } 3+\text { focal occurrence of }>16 \text { necrotic cells/HPF } \\
>16 \text { necrotic cells/HPF (extensive confluent necrosis) }\end{array}$ \\
\hline & Hemorrhage and fat necrosis \\
\hline $\begin{array}{l}0 \\
0.5 \\
1 \\
1.5 \\
2 \\
2.5 \\
3 \\
3.5 \\
4\end{array}$ & $\begin{array}{l}\text { absent } \\
1 \text { focus } \\
2 \text { foci } \\
3 \text { foci } \\
4 \text { foci } \\
5 \text { foci } \\
6 \text { foci } \\
7 \text { foci } \\
8 \text { foci }\end{array}$ \\
\hline & Inflammation and perivascular infiltrate \\
\hline $\begin{array}{l}0 \\
0.5 \\
1 \\
1.5 \\
2 \\
2.5 \\
3 \\
3.5 \\
4\end{array}$ & $\begin{array}{l}\text { 0-1 intralobular or perivascular leukocytes/HPF } \\
2-5 \text { intralobular or perivascular leukocytes/HPF } \\
6-10 \text { intralobular or perivascular leukocytes/HPF } \\
\text { 11-15 intralobular or perivascular leukocytes/HPF } \\
\text { 16-20 intralobular or perivascular leukocytes/HPF } \\
21-25 \text { intralobular or perivascular leukocytes/HPF } \\
26-30 \text { intralobular or perivascular leukocytes/HPF } \\
>30 \text { leukocytes/HPF or focal microabscesses } \\
>35 \text { leukocytes/HPF or confluent microabscesses }\end{array}$ \\
\hline
\end{tabular}

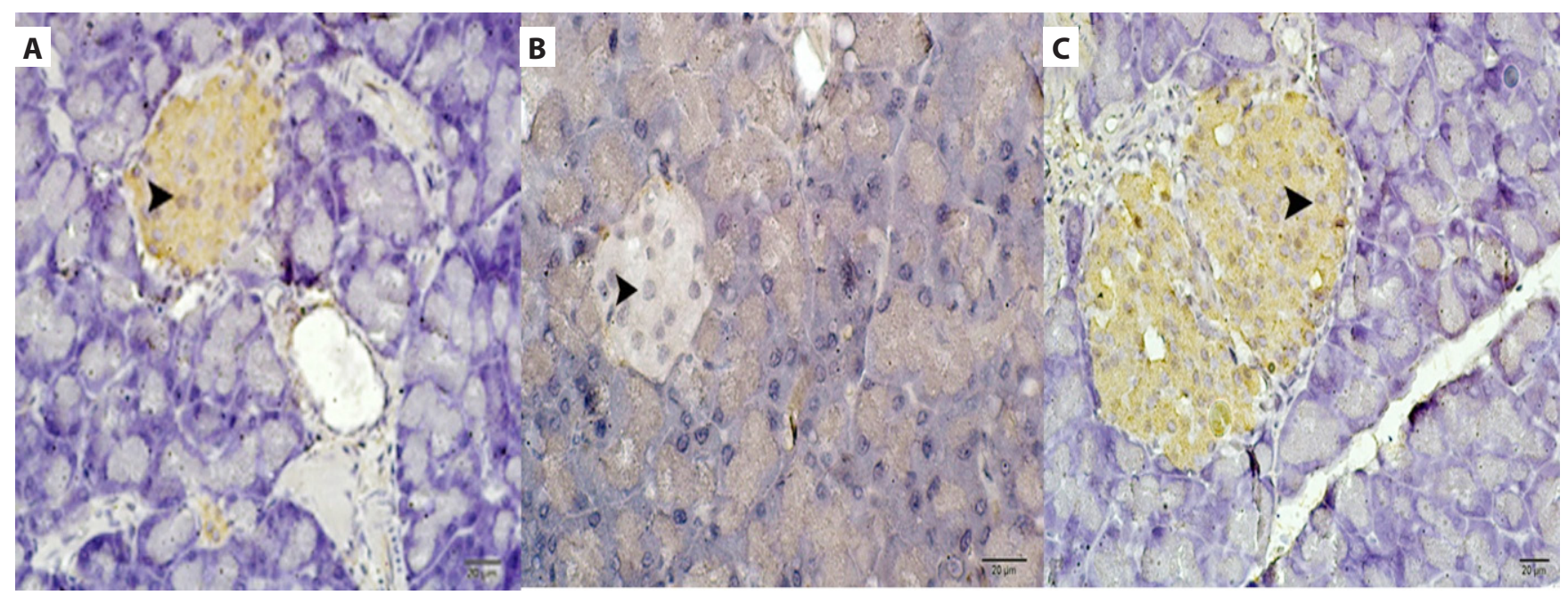

Fig. 2. Histopathologic examination of liver tissue stained by anti-insulin IHC staining method by light microscopy

A - control group, insulin positive area; B - MTX group, insulin negative area; C - MTX + ADA group, insulin positive area. 


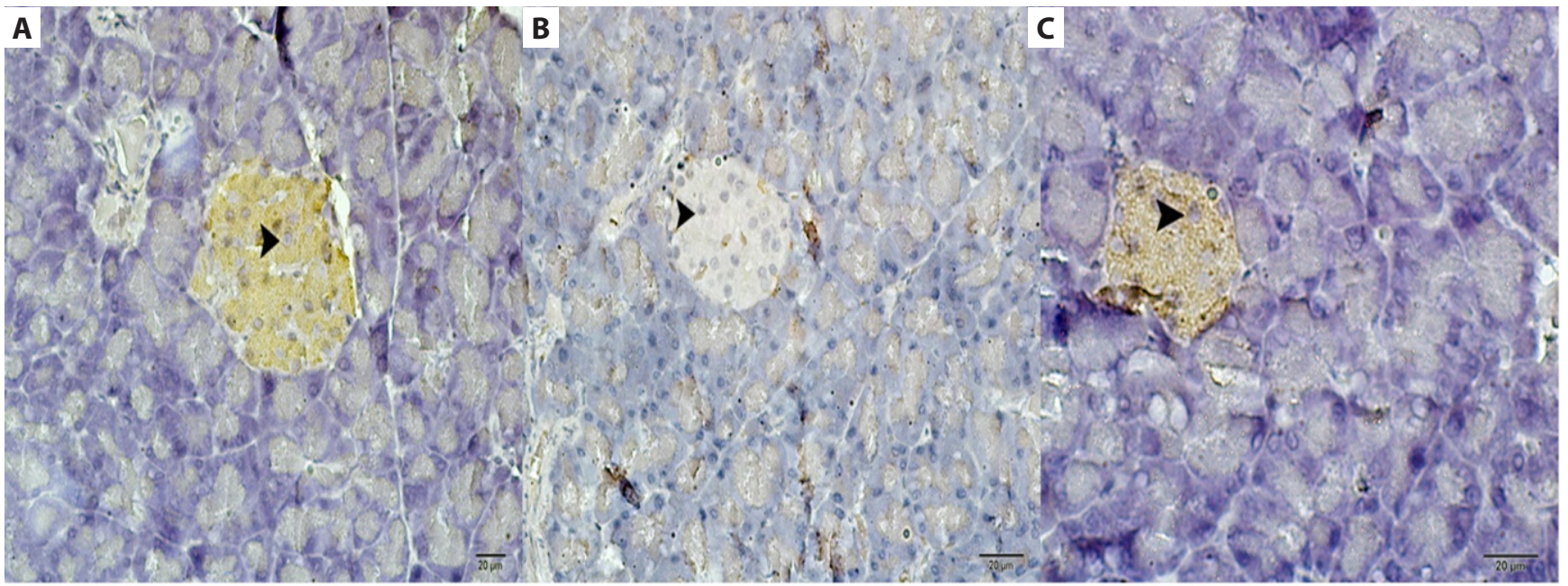

Fig. 3. Histopathologic examination of liver tissue stained by anti-somatostatin IHC staining method by light microscopy: A - control group, somatostatin positive area; B - MTX group, somatostatin negative area; C - MTX + ADA group, somatostatin positive area.

Table 2. Statistical results

\begin{tabular}{|l|c|c|c|c|c|} 
Treatment & $\begin{array}{c}\text { No. } \\
\text { of rats }\end{array}$ & Edema & $\begin{array}{c}\text { Acinar } \\
\text { necrosis }\end{array}$ & $\begin{array}{c}\text { Inflammatory } \\
\text { infiltration }\end{array}$ & $\begin{array}{c}\text { Perivascular } \\
\text { infiltration }\end{array}$ \\
\hline Control & 8 & $0.19 \pm 0.09^{b}$ & $0.13 \pm 0.08^{b}$ & $0.06 \pm 0.06^{b}$ & $0.06 \pm 0.06^{b}$ \\
\hline MTX & 8 & $1.75 \pm 0.66^{a}$ & $1.8 \pm 0.16^{a}$ & $1.88 \pm 0.08^{a}$ & $0.44 \pm 0.11^{a}$ \\
\hline MTX + ADA & 8 & $0.5 \pm 0.09^{b}$ & $0.56 \pm 0.6^{b}$ & $0.05 \pm 0.09^{b}$ & $0.13 \pm 0.08^{b}$ \\
\hline
\end{tabular}

Means in the same column by the same superscript letter are not statistically significantly different under the Tukey test $(a=0.05)$. Results are mean \pm standard error of the mean.

${ }^{a}$ vs control Group p $<0.05 ;{ }^{b}$ vs MTX Group p < 0.05. MTX - methotrexate; ADA - adalimumab.

Increased edema, acinar edema, and necrotic cells were observed in islets of Langerhans and acinar cells in Group 2, compared to those found in Group $1(\mathrm{p}<0.05)$ (Table 2) in our study on MTX-induced pancreatic toxicity. It was also found that atypical islets of Langerhans and connective tissue trabeculae were observed to increase considerably in volume. A reduction in the amount of insulin and somatostatin was also found. An accumulation of mast cells in the connective tissue was observed.

Table 3. Anti-insulin and anti-somatostatin shown in the pancreas tissues by the method of immunoperoxidase in immunohistochemical staining

\begin{tabular}{|l|c|c|}
\multicolumn{1}{|c|}{ Group } & $\begin{array}{c}\text { Anti-insulin } \\
\text { median } \pm \text { SD }\end{array}$ & $\begin{array}{c}\text { Anti-somatostatin } \\
\text { median } \pm \text { SD }\end{array}$ \\
\hline Control & $3 \pm 0.75$ & $3 \pm 1.17$ \\
\hline MTX & $1 \pm 0.52^{\mathrm{a}}$ & $1 \pm 0.41^{\mathrm{a}}$ \\
\hline MTX + ADA & $2.5 \pm 1.05^{\mathrm{b}, \mathrm{c}}$ & $2.5 \pm 1.05$ \\
\hline
\end{tabular}

a In the statistical evaluations performed, significant differences were observed between the control and MTX groups in terms of anti-insulin and anti-somatostatin immunopositivity according to the Kruskal-Wallis test $(p<0.05)$. ${ }^{b}$ In the statistical evaluations performed, significant differences were observed between the control and MTX + ADA groups in terms of anti-insulin and anti-somatostatin immunopositivity according to the Kruskal-Wallis test $(p<0.05)$. ${ }^{c}$ In the statistical evaluations performed, significant differences were observed between the MTX and MTX + ADA groups in terms of anti-insulin and anti-somatostatin immunopositivity according to the Kruskal-Wallis test $(p<0.05)$. MTX - methotrexate; ADA - adalimumab.

\section{Discussion}

The side effects of MTX on the pancreas have not been researched. However, high-dosage substances were reported to have a toxic effect on the pancreas. Irreversible tissue injury with edema, inflammation, and acinar necrosis was also found in histopathological studies on pancreatic toxicity. ${ }^{16-23}$
According to the literature, increased oxidative stress leads to the release of proinflammatory cytokines, leading to further tissue damage. ${ }^{22-24}$ Methotrexate is used for the treatment of pancreatic cancer, but has been shown to destroy the beta cells of the pancreas, primarily through oxidative stress. ${ }^{1,2,5,24}$ In support of the data in the literature, we determined that in our study the number of insulin and somatostatin-positive cells significantly decreased in Group 2, when compared to that in Group 1 (Fig. 2B, 3B).

It has been proposed in previous studies that MTX increases lipid peroxidation and oxidative stress, leading to an increase in reactive oxygen species (ROS)..$^{5,24}$ It has also been reported that ROS play a key role in decreasing immune system defense. ${ }^{5,24,25}$ In addition, intense proinflammatory cytokine release, due to excessive ROS formation, has been reported during MTX treatment for cancer and autoimmune diseases., 5,24,25 Accumulation of ROS leads to neutrophil infiltration and proinflammatory cytokine release, which triggers apoptosis. ${ }^{5,6,24,25}$ Methotrexate is used for the treatment of pancreatic cancer, but has been shown to destroy the beta cells of the pancreas, primarily through oxidative stress. ${ }^{5,6,24-26}$

A decrease in islets of Langerhans insulin and somatostatin-immunopositive cells was shown in this study following the administration of MTX (Fig. 2B, 3B). 
It has been suggested that TNF- $\alpha$ plays a key role in the mechanism of immune-mediated inflammation in recent studies. Inhibition of TNF results in the downregulation of abnormal and progressive inflammatory processes, resulting in target organ damage. ${ }^{4,5,10,11,19,27}$ It has been experimentally proven that TNF inhibitors prohibit organ tissue damage by suppressing the formation of TNF- $\alpha$, proinflammatory cytokines, and nitric oxide. ${ }^{5,26,27}$

A decrease in edema, acinar cell edema, and necrotic cells was observed in Group 3 ( $\mathrm{p}<0.05$ ) (Table 2) after the administration of ADA. An increase in islets of Langerhans insulin and somatostatin-positive cells was also demonstrated following the application of ADA treatment to Group 3 (Fig. 2C, 3C).

As a result, ADA was shown to have a protective effect against MTX-induced pancreatic injury. It was shown in this study that ADA reduced inflammatory levels and provided better protection to the insulin and somatostatin cells than that provided by MTX. This was a pilot study. Thus, further studies are needed in this regard to confirm our findings.

\section{References}

1. Sendur N, Karaman G, Savk E, Sahinkarakas E. Cutaneous ulceration as an early manifestation of methotrexate toxicity. T Klin J Med Sci. 2002;22:593-596.

2. Calvert AH, Walling JM. Clinical studies with MTA. Br J Cancer. 1998;78:35-40.

3. Selhub J, Dhar GJ, Rosenberg IH. Inhibition of folate enzymes by sulfasalazine. J Clin Invest. 1978;61:221-224.

4. Behrens F, Canete JD, Olivieri I, van Kuijk AW, McHugh N, Combe B. Tumour necrosis factor inhibitor monotherapy vs combination with Mtx in the treatment of PsA: A systematic review of the literature. Rheumatology. 2015;54:915-926.

5. Cure E, Kirbas A, Tumkaya L, et al. Protective effect of infliximab on methotrexate-induced liver injury in rats: Unexpected drug interaction. J Cancer Res Ther. 2015;11:164-169.

6. Moghadam AR, Tutunchi S, Namvaran-Abbas-Abad A, et al. Preadministration of turmeric prevents methotrexate-induced liver toxicity and oxidative stress. BMC Complement Altern Med. 2015;15:246.

7. Kanter M, Yuncu M. Protective effects of vitamin E against methotrexate-induced mucosal damage of the small intestine in mice: An electron microscopic study. TAD Journal. 2006;4:1-6.

8. Güzel R. Rheumatoid arthritis and disease modifying antirheumatic drugs. Turk J Phys Med Rehab. 2008;54:25-30.

9. Salzer WL, Devidas M, Shuster JJ, et al. Intensified PEG-L-asparaginase and antimetabolite-based therapy for treatment of higher risk precursor-B acute lymphoblastic leukemia: A report from the Children's Oncology Group. J Pediatr Hematol Oncol. 2007;29:369-375.

10. Lipsky PE, van der Heijde DM, St. Clair EW, et al. Infliximab and methotrexate in the treatment of rheumatoid arthritis. $N$ Engl J Med. 2000;30:1594-1602.

11. Harriman G, Harper LK, Schaible TF. Summary of clinical trials in rheumatoid arthritis using infliximab, an anti-TNF/E treatment. Ann Rheum Dis. 1999;58:161-164. doi:10.1056/NEJM200011303432202

12. Goto Y, Yue L, Yokoi A, et al. A novel single-nucleotide polymorphism in the $3^{*}$-untranslated region of the human dihydrofolate reductase gene with enhanced expression. Clin Cancer Res. 2001;7:1952-1956.

13. Schmiegel W, Roeder C, Schmielau J, Rodeck U, Kalthoff H. Tumor necrosis factor alpha induces the expression of transforming growth factor alpha and the epidermal growth factor receptor in human pancreatic cancer cells. Proc Natl Acad Sci. 1993;90:863-867.
14. Schmidt J, Rattner DW, Lewandrowski K, et al. A better model of acute pancreatitis for evaluating therapy. Ann Surg. 1992;215:44-56.

15. Tinder TL, Subramani DB, Basu GD, et al. MUC1 enhances tumour progression and contributes toward immunosuppression in a mouse model of spontaneous pancreatic adenocarcinoma. J Immunol. 2008;181:3116-3125.

16. Gokalp O, Karakoyun I, Kaleli S, Ozer MK, Gultekin F. The effects of chlorpyrifos-ethyl on pancreas in rats. Journal of Suleyman Demirel University Medicine. 2005;12:19-22.

17. Gardi JE, Nyengaard JR, Gundersen HJ. Automatic sampling for unbiased and efficient stereological estimation using the proportionator in biological studies. J Microsc. 2005;230:108-120.

18. Maruyama H, Nakatsuji N, Sugihara S, et al. Anaplastic Ki-1-positive large cell lymphoma of the pancreas: A case report and review of the literature. Jpn J Clin Oncol. 1997;27:51-57.

19. Tasaka $\mathrm{Y}$, Nakaya F, Matsumoto $\mathrm{H}$, Omori Y. Effects of aminoguanidine on insulin release from pancreatic islets. Endocr J. 1994;41:309-313.

20. Hiramatsu S, Inoue K, Sako Y, Umeda F, Nawata H. Secretion of insulin and glucagon by the perfused pancreas of genetically obese $(\mathrm{fa} / \mathrm{fa})$ Zucker rats and its alteration with aging. Endocr J. 1995;42:563-567.

21. Kimura N, Schindler M, Kasai N, Kimura I. Immunohistochemical localization of somatostatin receptor type $2 \mathrm{~A}$ in rat and human tissues. Endocr J. 2001;48:95-102.

22. Tasaka Y, Nakaya H, Omori Y. Effects of aminoguanidine on glucagon and insulin release from rat pancreatic islet. Endocr J. 1996;43:725-730.

23. Heitz PU, Kasper M, Polak JM, Kloppel G. Pathology of the endocrine pancreas. J Histochem Cytochem. 1979;27:1401-1402.

24. Sampaio AF, Silva M, Dornas WC, et al. Iron toxicity mediated by oxidative stress enhances tissue damage in an animal model of diabetes. Biometals. 2014;27:349-361.

25. Kalkan Y, Tumkaya L, Bostan $H$, et al. Effect of sugammadex on rocuronium induced changes in pancreatic mast cells. Toxicol Ind Health. 2015;31:738-746.

26. Tanaka T, Sekine A, Tsunoda Y, et al. Central nervous system manifestations of tuberculosis-associated immune reconstitution inflammatory syndrome during adalimumab therapy: A case report and review of the literature. Intern Med. 2005;54:847-851.

27. Rau R. Adalimumab (a fully human anti-tumour necrosis factor a monoclonal antibody) in the treatment of active rheumatoid arthritis: The initial results of five trials. Ann Rheum Dis. 2002;61:70-73. 